\title{
Ultrasound Study of First Trimester Bleeding
}

\author{
Mathurin Neossi Guena1,2*, Florent Zilbinkai Alapha², Doris Christelle Maleu Kemegne1, \\ Achille Nkigoum Nana ${ }^{3}$, Odile Fernande Zeh",5, Joseph Gonsu Fotsing ${ }^{4,5}$
}

\author{
${ }^{1}$ Department of Biomedical Sciences, Faculty of Sciences, University of Ngaoundéré, Ngaoundéré, Cameroon \\ ${ }^{2}$ Imaging Service, Ngaoundéré Regional Hospital, Ngaoundéré, Cameroon \\ ${ }^{3}$ Gyneacology and Obstetrical Service, Ngaoundéré Regional Hospital, Ngaoundéré, Cameroon \\ ${ }^{4}$ Faculty of Medicine and Biomedical Sciences, University of Yaounde I, Yaounde, Cameroon \\ ${ }^{5}$ Yaounde Gynaecology Obstetrics and Pediatrics Hospital, Yaounde, Cameroon \\ Email: ^mneossiguena@yahoo.fr
}

How to cite this paper: Neossi Guena, M., Zilbinkai Alapha, F., Maleu Kemegne, D.C., Nkigoum Nana, A., Zeh, O.F. and Gonsu Fotsing, J. (2019) Ultrasound Study of First Trimester Bleeding. Open Journal of Radiology, 9, 58-68.

https://doi.org/10.4236/ojrad.2019.91006

Received: January 16, 2019

Accepted: February 25, 2019

Published: February 28, 2019

Copyright $\odot 2019$ by author(s) and Scientific Research Publishing Inc. This work is licensed under the Creative Commons Attribution International License (CC BY 4.0).

http://creativecommons.org/licenses/by/4.0/

\begin{abstract}
Objective: Bleeding during the first trimester of pregnancy is common and can be a sign of complication that often necessitates obstetric ultrasound for the assessment of the haemorrhage, and of fetal well being. The aim of this study was to determine the causes of first trimester bleeding on obstetrical ultrasound in our area. Method: It was a cross-sectional descriptive study during a six-month period from May to October 2017. All women who referred to the Regional center of medical imaging of Ngaoundere who agreed to participate in the study with first trimester bleeding were evaluated with clinical history and ultrasonography (US). Ultrasonographic exam was done via transabdominal or endovaginal approaches using GE LOGIQ 7 scanner brand. Microsoft Office Excel 2010 and SPHINX V 4.0 were used for data analysis. Results: A total of 121 of pregnant women who presented vaginal bleeding during the first trimester were enrolled into the study. These Ultrasound examinations represented $37.93 \%$ of all obstetric ultrasounds in the first trimester. The patients in this study ranged in age from 16 to 47 years with an average of 30 years. $50(41.32 \%)$ were pregnant for the first time and $24(19.83 \%)$ were primiparous. Mean gestational age was 9 weeks with the extremes of 5 and 12 weeks. 97 (80.2\%) reported spontaneous bleeding while in $24(18.8 \%)$ bleeding was mostly caused by sexual intercourse $11(45.8 \%)$. Pelvic pain 91 (75.2\%) was the most associated sign. 36 (29.8\%) patients were diagnosed as threatened abortions. 27 (22.3\%) were diagnosed with incomplete abortions. $4(3.3 \%)$ cases showed an ectopic gestation. 9 (7.4\%) cases showed complete abortions. Concordance between clinical diagnosis and ultrasound results was $84 \%$. Conclusions: Bleeding in the first trimester of pregnancy is common in our area. Ultrasonography occupies a prominent place in the etiological diagnosis of bleeding in the first trimester of pregnancy; it
\end{abstract}


is easy to find in most cases a responsible abnormality of bleeding.

\section{Keywords}

Bleeding of the First Trimester, Pregnancy, Ultrasound, Etiological Diagnosis

\section{Introduction}

First trimester bleeding is common in the emergencies and occurs to pregnant women who are 12 weeks or less of amenorrhea [1]. Spotting is the most common cause of bleeding caused by implantation of the conceptus into the endometrium. The occurrence of first trimester bleeding per vaginum is estimated to be as high as $7 \%$ to $24 \%$ in early pregnancies [2]. About $50 \%$ of first Trimester bleeding lead to miscarriage; the primary causes of first trimester bleeding are spontaneous abortions, ectopic pregnancies, and gestational trophoblastic diseases [3]. The diagnosis is usually clinical, based on physical examination and clinical history and is confirmed by ultrasound. Since its introduction, technology has increased. Endovaginal ultrasonography represented a significant enhancement of this technology decreasing maternal morbidity and mortality. Now it is possible to detect an intrauterine gestational sac as early as five weeks. Clinical history and pelvic examination are often inadequate in assessing the cause and the prognosis. When ultrasonography reveals the nature of the pregnancy (viable/non-viable), unnecessary complications and misdiagnosis in first trimester bleeding can be avoided [2]. But the unavailability of ultrasound devices and trained practitioners limit the use of this exam. Therefore this study was undertaken for assessment of bleeding in the first trimester of pregnancy at the Regional Hospital of Ngaoundere to identify the main causes whose knowledge can improve their management even in the absence of ultrasound.

\section{Methods}

We carried out a descriptive cross-sectional study. It took place at the Regional Center for Medical Imaging of Ngaoundere Regional Hospital from May to October 2017. This study included all patients up to 12 weeks of gestational age who agreed to participate in the study with first trimester bleeding referred to the center for ultrasonography examination. All patients with non-obstetrical causes of vaginal bleeding and whose records were not complete were excluded. Sampling was consecutive and exhaustive non probabilistic. Data was collected from the radiologist report and request forms of patients. All the patients were scanned using GE LOGIQ 7 Ultrasound. These studies was done using either a 3.5 $\mathrm{MHz}$ probe trans abdominal. Transvaginal ultrasonography was performed when the patient's bladder was empty and when the gestational week was 7 weeks or less, using $4.2-6.5 \mathrm{MHz}$ endocavitory probe. The variables studied were age, profession, gravidity, parity, heaviness of bleeding, ultrasound results 
and concordance rate between clinical diagnosis and ultrasound diagnosis. To determine the amount of bleeding, it is based on the condition of the sanitary napkins during the duration of bleeding, if we observe that a point on the towel, we speak of spotting, if the towel partially soaked, the bleeding is light, if the towel is completely soaked with debortment and blood clots one speaks of heavy bleeding. The concordance rate was calculated as the ratio of the number of ultrasound diagnosis to the number of clinical diagnosis multiplied by one hundred. During ultrasound examination, the following findings was noted like uterine size, presence and location of the gestational sac, crown rump length (CRL), cardiac activity, foetal movements, presence or absence of foetal pole an finally a study of adnexa and presence of any free fluid in the cul-de-sac. All the data collected were analyzed using Microsoft Excel 2010 and Sphinx version 4.0 to produce frequency tables and charts. There was cross tabulations to explore relationship between variables. Ethical approval was obtained from the ethical Committee of Ngaoundere Regional Hospital

\section{Results}

One hundred and twenty one (121) women aged between 16 and 47 years old with an average of 30 years were enrolled in this study. The modal age group was 30 to 34 years old representing 31.4\% (Table 1), Most were housewives 54 (44.6\%) and students 22 (18.1\%) (Table 2). 50 (41.32\%) were pregnant for the first time and $24(19.83 \%)$ were primiparous. Mean gestational age was 9 weeks with the extremes of 5 and 12 weeks, the 6 to 10 weeks period were predominant (Table 3). $97(80.2 \%)$ reported spontaneous bleeding while in 24 (18.8\%) bleeding was caused, mostly by sexual intercourses 11 (45.8\%) (Table 4$)$. The $36(29.8 \%)$ patients were diagnosed as threatened abortions. 27 (22.3\%) was diagnosed with incomplete abortions. 4 (3.3\%) cases showed an ectopic gestation. 9 (7.4\%) cases showed complete abortions (Table 5 ).

There was a statistically significant relation $(\mathrm{p}=0.001)$ between ultrasonography findings and the heaviness of bleeding (Table 6). There was a statistically significant relation $(p=0.002)$ between Ultrasonography results and the presence of blood clots and retained product of conception (Table 7). We notice that

Table 1. Distribution of patients by age group.

\begin{tabular}{ccc}
\hline Age group & Frequency & Percentage (\%) \\
$\leq 25 y$ & 9 & 7.4 \\
$26-29 y$ & 33 & 27.3 \\
$30-34 y$ & 38 & 31.4 \\
$35-39 y$ & 20 & 16.5 \\
$40-44 y$ & 18 & 14.9 \\
$\geq 45 y$ & 3 & 2.5 \\
Total & 121 & 100 \\
\hline
\end{tabular}


Table 2. Distribution of patients by profession.

\begin{tabular}{ccc}
\hline Profession & Frequency & Percentage (\%) \\
\hline Housewife & 54 & 44.6 \\
Student & 22 & 18.1 \\
Dressmaker & 12 & 9.9 \\
Teacher & 10 & 8.3 \\
Tradeswoman & 6 & 5 \\
Nurse & 4 & 3.3 \\
Secretary & 3 & 2.5 \\
Farmer & 2 & 1.7 \\
Other* & 8 & 6.6 \\
TOTAL & 121 & 100 \\
\hline
\end{tabular}

${ }^{\star}$ Other $=$ cashier, hairdresser, accountant, journalist, veterinary.

Table 3. Distribution of patient by gestational age, gravidity and parity.

\begin{tabular}{ccc}
\hline & Frequency & Percentage (\%) \\
\hline Gestational age & 12 & 11.4 \\
$-\quad 6$ weeks & 79 & 75.2 \\
$-\quad 10$ to 12 weeks & 14 & 13.3 \\
Gravidity & & 41.32 \\
- Primigravida & 50 & 58.67 \\
- Multigravida & 71 & \\
Parity & & 19.83 \\
- Primipara & 24 & 43.8 \\
\hline
\end{tabular}

Table 4. Distribution of patient by the causes and heaviness of bleeding.

\begin{tabular}{lcc}
\hline & Frequency & Percentage (\%) \\
\hline Bleeding & 97 & 80.2 \\
- Spontaneous & 24 & 18.8 \\
- Caused & & \\
Heaviness of bleeding & 54 & 44.6 \\
- Spotting & 34 & 28.1 \\
- Light & 33 & 27.3 \\
- Heavy & & \\
Circumstances of occurrence & 11 & 9.9 \\
- Sexual intercourse & 3 & 2.47 \\
- Physical effort & 10 & 8.26 \\
\hline
\end{tabular}

${ }^{*}$ Other $=$ road accident, personal hygiene. 
Table 5. Ultrasonography examination findings.

\begin{tabular}{ccccc}
\hline USG Diagnosis & Gupta N et al. [2] & Aronu et al. [3] & Priso B et al. [4] Present study \\
\hline Threatened abortions & $72(36 \%)$ & $66(65.3 \%)$ & $73(27.2 \%)$ & $36(29.8 \%)$ \\
Incomplete abortions & $40(20 \%)$ & $7(6.9 \%)$ & $26(9.7 \%)$ & $27(22.3 \%)$ \\
Stopped pregnancy & - & - & $55(20.5 \%)$ & $22(18.2 \%)$ \\
Normal pregnancy & - & - & $14(5.2 \%)$ & $19(15.7 \%)$ \\
Complete abortions & $24(12 \%)$ & $9(8.9 \%)$ & $12(4.5 \%)$ & $9(7.4 \%)$ \\
Ectopic gestation & $16(8 \%)$ & $3(3 \%)$ & $1(0.4 \%)$ & $4(3.3 \%$ \\
Anembryonic gestation & $8(4 \%)$ & $1(1 \%)$ & $33(12.3 \%)$ & $3(2.5 \%)$ \\
Molar pregnancy & $8(4 \%)$ & $3(3 \%)$ & $7(2.6 \%)$ & $1(0.8 \%)$ \\
\hline
\end{tabular}

Table 6. Distribution of ultrasonography examination by the heaviness of bleeding.

\begin{tabular}{ccccc}
\hline & \multicolumn{5}{c}{ Bleeding } \\
\hline USG findings & Heavy & light & Spotting & Total \\
\hline Threatened abortions & 4 & 9 & 23 & 36 \\
Incomplete abortions & 17 & 7 & 3 & 27 \\
Stopped pregnancy & 3 & 12 & 7 & 22 \\
Normal pregnancy & 1 & 3 & 15 & 19 \\
Complete abortions & 6 & 1 & 2 & 9 \\
Ectopic gestation & 1 & 1 & 2 & 4 \\
Anembryonic Gestation & 1 & 1 & 1 & 3 \\
Molar pregnancy & 0 & 0 & 1 & 1 \\
TOTAL & 33 & 34 & 54 & 121 \\
\hline
\end{tabular}

Table 7. Distribution of ultrasonography results by the presence of blood clots and retained product of conception.

\begin{tabular}{ccccc}
\hline & \multicolumn{2}{c}{ Blood clots } & \multicolumn{2}{c}{ Retained products of conception } \\
\hline USC results & Yes & No & Yes & No \\
\hline Threatened abortions & 13 & 23 & 3 & 33 \\
Incomplete abortions & 22 & 5 & 2 & 25 \\
Stopped pregnancy & 11 & 11 & 4 & 18 \\
Normal pregnancy & 4 & 15 & 1 & 7 \\
Complete abortions & 6 & 3 & 2 & 4 \\
Ectopic gestation & 3 & 1 & 0 & 2 \\
Anembryonic Gestation & 1 & 2 & 1 & 1 \\
Molar pregnancy & 0 & 1 & 0 & 108 \\
Total & 60 & 61 & 13 & \\
\hline
\end{tabular}

patients with incomplete abortions had blood clots during bleeding. Therefore there is no statistically significant relation between ultrasound results and the 
existence of retained products of conception $(\mathrm{P}=0.056)$. The confrontation between the clinical diagnosis and the ultrasound results showed a concordance rate of $84 \%$ (Table 8 ).

\section{Discussion}

A total of 121 of pregnant women who presented vaginal bleeding during the first trimester referred to the center for an ultrasonography examination were enrolled into the study. These ultrasound examinations represented $37.93 \%$ of all obstetric ultrasounds in the first trimester, so this is a common pattern of ultrasound. The 121 women in this study ranged in age from 16 to 47 years with an average of 30 years. The target for these disturbances is logically made up of women of childbearing age. Patients aged between 30 and 34 years (31.4\%) were more represented. This rate is in accordance with findings reported in similar studies [3] [4]. Most of them were housewives with a rate of $44.6 \%$ comparable to those of Albachar and Diarisso who had found a rate of $49.4 \%$ and $69.1 \%$ respectively [5] [6]. This higher rate of housewives confirms that in our socio-professional structure housewives are the most numerous. Most of them were multigravidas (80.2\%) and pimiparous (56.2\%). The risk of bleeding increased with a large number of gesture due to dynamic changes of the uterus and cervix which become weak [5]. This bleeding occurs at all gestational ages between the implantation of the embryo in the uterus and 12 SA, mostly between 6 - 10 weeks in $75.2 \%$ in our serie and $50.8 \%$ in that of Boco [7]. This period which follows the implantation of the conceptus into the endometrium remains fragile.

In our study, $97(80.2 \%)$ women reported spontaneous bleeding while 24 (18.8\%) bleeding were caused, mostly by sexual intercoursies 11 (45.8\%). Indeed this period of pregnancy is delicate and the bleeding can occur even if the trauma is minimal.

The heaviness of bleeding occurring during first trimester pregnancies varies according to the etiology $(\mathrm{p}=0.001)$. Patients with incomplete abortions had such heavy bleeding as those with complete abortions. It is important to estimate the heaviness of bleeding and to look for associated signs in order to assess the

Table 8. Confrontation between clinical and USG based diagnosis.

\begin{tabular}{cccc}
\hline Category & Clinical diagnosis & USG diagnosis & Normal USG \\
\hline Threatened abortions & 46 & 36 & 9 \\
Incomplete abortions & 35 & 27 & 5 \\
Stopped pregnancy & 26 & 22 & 3 \\
Complete abortions & 13 & 9 & 2 \\
Ectopic gestation & 1 & 4 & 0 \\
Anembryonic Gestation & 0 & 3 & 0 \\
Molar pregnancy & 0 & 1 & 0 \\
Total & $121(100 \%)$ & $102(84 \%)$ & $19(16 \%)$
\end{tabular}


patient's hemodynamic status and evoking the etiology. The most common associated sign in our series is pain as and in the literature [6].

As ultrasonography findings, threatened abortion (29.8\%) was the commonest cause of first trimester vaginal bleeding. This similar trend was observed in other studies [2] [3] [4] [7] [8]. Threatened abortion is the result of marginal abruption with separation of the chorion from the endometrial lining and subchorionic hemorrhage which can lead to an abortion. On ultrasonography, subchorionic hemorrhage (Figure 1) is either hypoechoic or echoic depending on the age of the blood products at the time of the US examination [4].

$27(22.3 \%)$ women were diagnosed with incomplete abortions. This rate is comparable to that of Yang and al, who found a rate of $23.1 \%$ [9]. Persistent vaginal bleeding after an abortion may be due to retained trophoblastic tissue, but these women may also present with symptoms of infection, including pain and fever [10]. Findings on US are heterogeneous hypoechoic material in the endometrial cavity consistent of retained trophoblastic tissue and blood clots (Figure 2).

There were 22 (18\%) cases of stopped pregnancies (fetal demise). Belley Priso and al found a rate of $20 \%$. As US features, there was an ovular gestational sac containing an embryo with no cardiac activity detected [4]. This may occur during the early stages of pregnancies usually under 10 weeks gestational age.

Bleeding from an ectopic pregnancy is the most dangerous cause of first trimester bleeding. It concerned 3.3\% of the cases in our study. Belley and al found a rate of $5.2 \%$. It occurs when the fertilized egg is implanted outside of the uterus, most often in the Fallopian tube. The ultrasonographic finding was the visualization of an annular adnexal mass containing a viable embryo or not (Figure 3), sometimes with a hemoperitoneum with an empty uterus [4]. The incidence is higher in patients with a history of prior ectopic pregnancy, previous pelvic inflammatory disease, tubal disease, presence of an intrauterine device, and in those undergoing in vitro fertilization [11].

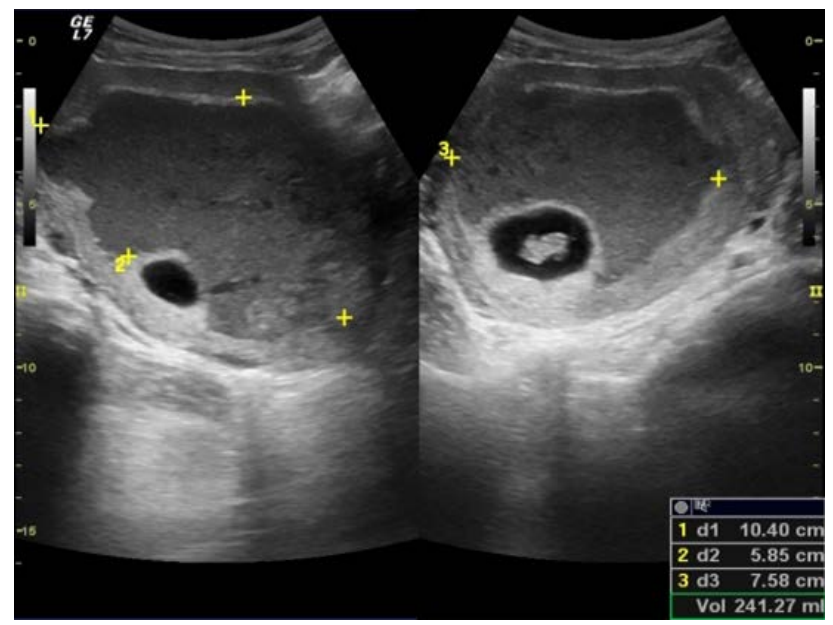

Figure 1. USG shows a massive subchorionic hemorrhage (calipers) surrounding the gestational sac. 

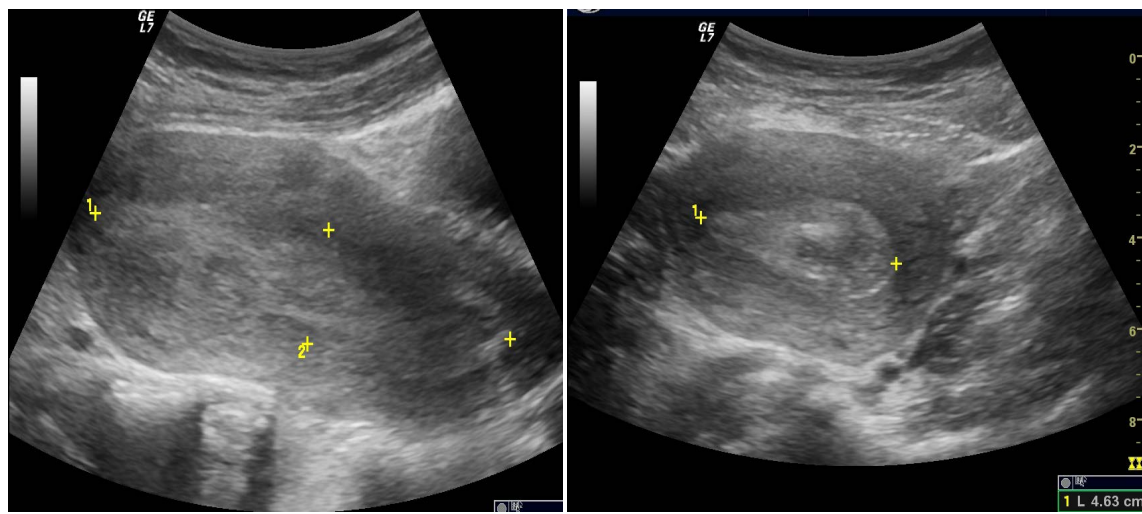

Figure 2. Retained products of conception in the uterine cavity.
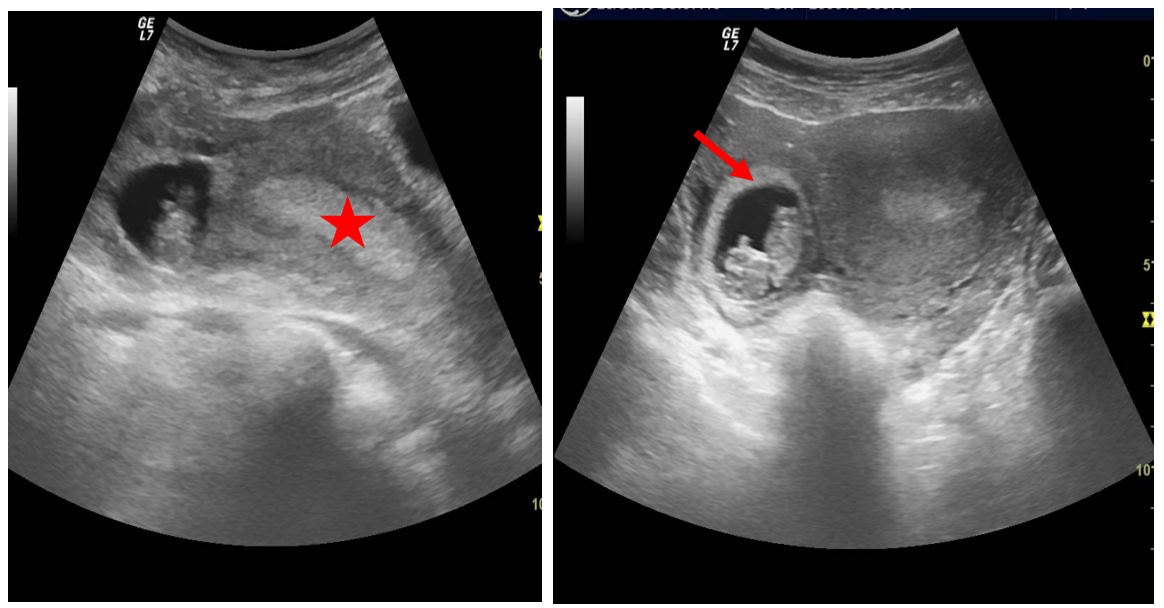

Figure 3. Abnormal location of the gestational sac (red arrow) in the right side of the empty uterus (red star).

$9(7.4 \%)$ were diagnosed as complete abortion. This rate is similar to those of Coulibaly who found a rate of $9.1 \%$ [1]. The causes of this are various, the presence of myomas, the genetic abnormalities, the infectious diseases such as malaria. The uterus appears to be empty based on ultrasound evaluation.

An anembryonic pregnancy (blighted ovum) is an early failure of the embryo to develop within the GS. 3 (2.5\%) patients were diagnosed with blighted ovum. Diarisso in 2011 found a rate of 4.3\% [6]. The ultrasonographic finding was the visualization of a gestational sac within the uterus with an irregular contour without embryos which can contain a Yolk sac (Figure 4).

Molar pregnancy is the most common gestational trophoblastic disease. It results from the fecundation of a single egg with no active nucleus, which means all the chromosomes present in the hydatidiform mole are paternal [12]. It was diagnosed in one patient $(0.8 \%)$ which is less than those found in similar studies [2] [3] [4] [7]. Ultrasound examination showed a heterogeneous echogenic endometrial mass with multiple variable-sized cysts ("Swiss cheese" or "snowstorm" endometrium) and no visible embryo (Figure 5).

Correct management of cases depends on correct diagnosis. In our study 


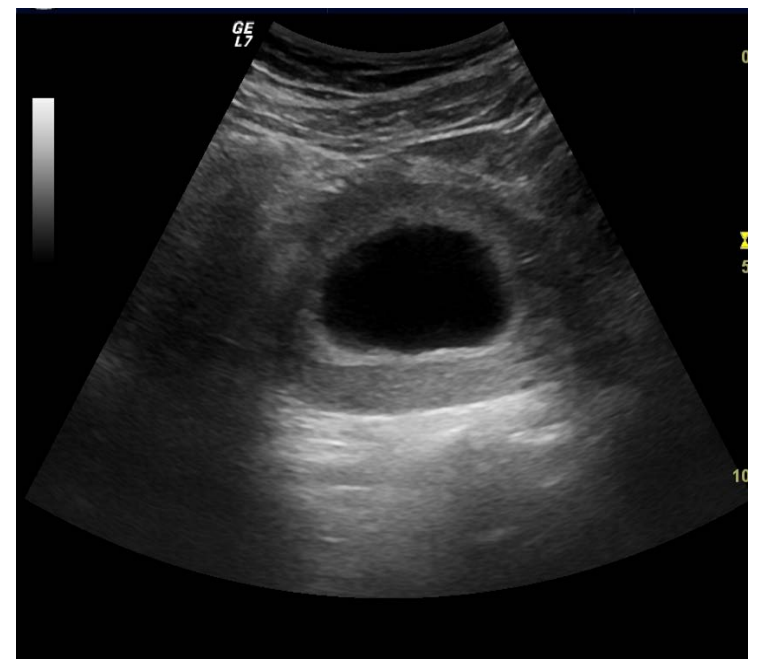

Figure 4. Gestational sac without an embryo.

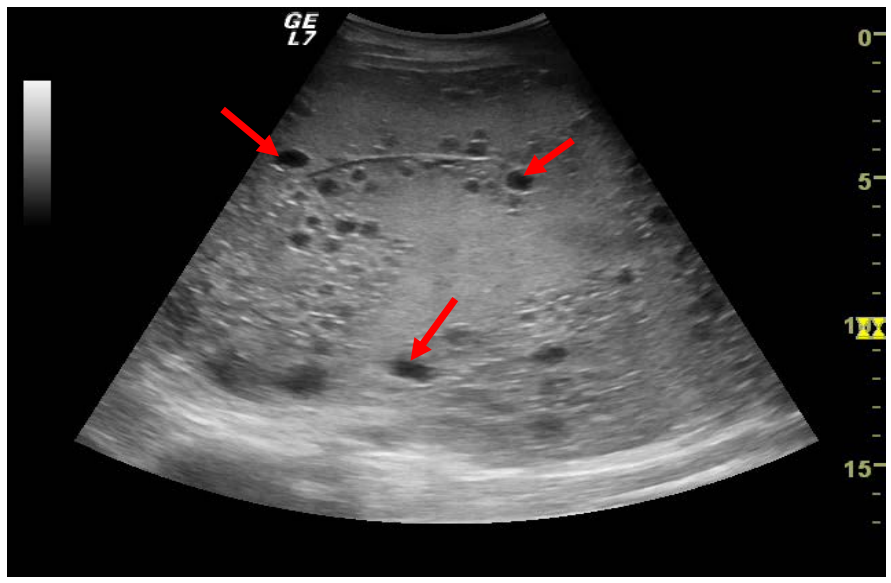

Figure 5. Complex mass in the uterine cavity with multiple tiny cystic spaces within it (red arrows) compatible with a hydatidiform mole.

concordance between clinical diagnosis and ultrasonographic diagnosis was $84 \% .3(2.5 \%)$ cases of anembryonic gestation and $1(0.8 \%)$ case of molar pregnancy were diagnosed based on USG, none of them were diagnosed clinically. This concordance rate in our study is relatively high, but low compared to most studies where the concordance rate varies from $96 \%$ to $100 \%$ [3], this is certainly due to the disparity in the level of precrisptors which varies from nurse to obstetric gynecologist through midwives. Aronu and al found that the highest concordance between clinical diagnosis and ultrasonographic diagnosis was observed in Obstetrics and Gynecology specialist group [3]. There was a statistically significant relation $(\mathrm{p}=0.001)$ between ultrasonography findings and the heaviness of bleeding. Patients with incomplete abortions had heavy bleeding than those with complete abortions. While those with stopped pregnancies had a light bleeding even when it's well known that among intrauterine pregnancies, light bleeding or spotting of short duration does not increase the risk of miscarriage [13]. There was a statistically significant relation $(\mathrm{p}=0.002)$ between Ultrasono- 
graphy results and the presence of blood clots and retained product of conception. We noticed that patients with incomplete abortions had blood clots during bleeding. Therefore there is no statistically significant relation between ultrasound results and the existence of retained products of conception $(\mathrm{P}=0.056)$. In normal viable intra uterine pregnancy bleeding was spontaneous or induced coming from the closed cervix. Heavy bleeding occurred mainly in incomplete and complete abortions, while spotting and light bleeding occurred in threatened abortions, viable intra uterine pregnancy and stopped pregnancies. Pelvic pain $91(75.2 \%)$ was the most reported associated sign. In threatened abortions, stopped pregnancies, incomplete and complete abortions, the bleeding was spontaneous which comes from the uterus. Threatened abortions, incomplete abortion, stopped pregnancy, molar pregnancy and ectopic pregnancy were characterized by metrorrhagia, pelvic pain, adnexal mass, an open or not cervix and were confirmed only on ultrasound, which was the only way to diagnose ectopic pregnancy, anembryonic pregnancy, and molar pregnancy [14].

\section{Limit of the Study}

Nonspecific sonographic findings in a patient with first trimester bleeding should be correlated with serum beta hCG levels to arrive at an appropriate clinical diagnosis, what is not the case in our study and what makes the diagnosis often difficult. Limitations of this study also include the difficulty to assess the outcome of pregnancies, most of the patients did not come back to attend their prenatal follow-up.

\section{Conclusion}

Bleeding in the first trimester pregnancies is a very common obstetrical problem, indeed is a frequent cause for assessing ultrasound scans at the regional hospital of Ngaoundere. It is a source of anxiety both to the patients and the obstetrician. This study shows that it is the common problem in 26 - 34 age pregnant women. The most common causes of first trimester bleeding are threatened abortions, incomplete abortions, stopped pregnancies, complete abortions, ectopic gestation, anembryonic gestation and molar pregnancy. $15.7 \%$ of pregnancies with first trimester bleeding are normal. Our study has shown the low concordance between clinical diagnosis and ultrasonographic diagnosis compared to other studies. This highlights the need for availability of ultrasound devices and trained sonographers to guide the clinician for better management of cases.

\section{Conflicts of Interest}

The authors declare that there is no conflict of interests regarding the publication of this paper.

\section{References}

[1] Coulibaly, N. (2010) Study of the First Trimester of Bleeding in the Gynecology and 
Obstetrics Department of the Reference Health Center of Commune V of BAMAKO District. End of Study Medicine Thesis, University of Bamako, Mali.

[2] Gupta, N., Samariya, M., Choudhary, D., Yadav, K. and Kannoujiya, P. (2016) Ultrasonographic Evaluation of First Trimester Bleeding per Vaginum. International Journal of Reproduction, Contraception, Obstetrics and Gynecology, 5, 3085-3087. https://doi.org/10.18203/2320-1770.ijrcog20162990

[3] Aronu, M.E., et al. (2018) A Review of the Correlation between Clinical Diagnosis and Ultrasound Diagnosis in First Trimester Vaginal Bleeding. Annals of Medical and Health Science Research, 8, 120-124.

[4] Belley Priso, E., Moifo, B., Zeh, O.F., Nana Njamen, T., Foumane, P., Nguemgne, C., Ayuk, P.A. and Mboudou, E. (2010) Contribution of Emergency Ultrasonography in the Management of Bleeding during the First Trimester of Pregnancy at the Douala General Hospital. African Journal of Medical Imaging, 3, 187-196.

[5] Albachar, $\mathrm{H}$ (2006) Les hémorragies du premier trimestre de la grossesse au centre de sante de référence de la commune VI. Thèse Med, Bamako, No. 203.

[6] Diarisso, A. (2012) First Trimester Hemorrhages at Nianankorofomba de Segou hospital. End of Study Medicine Thesis, University of Bamako, Mali, 90 p.

[7] Boco, V., Akpovi, J., Takpara, I., Latoundji, M.C., Lantokpode, J.C. and Perrin, R. (1997) Interest of Ultrasound in Metrorrhagia of the First Trimester Pregnancy. Medicine d Afrique Noire, 44, 97-100.

[8] Kane, B. (2011) Study of Bleeding in the First Trimester of Pregnancy at the Bougouni Reference Health Center. End of Study Medicine Thesis, University of Bamako, Mali, 117 p.

[9] Yang, J., Hartmann, K., Savitz, D., Herring, A., Dole, N., Olshan, A., et al. (2004) Vaginal Bleeding During Pregnancy and Preterm Birth. American Journal of Epidemiology, 160, 118-125. https://doi.org/10.1093/aje/kwh180

[10] Vidya, A., Guruvaj, D., Uma, A. and Rum, N. (2016) Ultrasonographic Evaluation of First Trimester Vaginal Bleeding. Al Ameen Journal of Medical Sciences, 9, 107-111.

[11] Dighe, M., Cuevas, C., Moshiri, M., Dubinsky, T. and Dogra. V.S. (2008) Sonography in First Trimester Bleeding. Journal of Clinical Ultrasound, 36, 352-366. https://doi.org/10.1002/jcu.20451

[12] Levine, D. (2007) Ectopic Pregnancy. Radiology, 245, 385-397. https://doi.org/10.1148/radiol.2452061031

[13] Hasan, R., Baird, D.D., Herring, A.H., Olshan, A.F., Jonsson Funk, M.L. and Hartmann, K.E. (2009) Association between First-Trimester Vaginal Bleeding and Miscarriage. Obstetrics \& Gynecology, 114, 860-867. https://doi.org/10.1097/AOG.0b013e3181b79796

[14] Singh, K. (2016) Assessment of First Trimester Vaginal Bleeding Using Ultrasound Sonography. Asian Journal of Biomedical and Pharmaceutical Sciences, 6, 54-56. 